Hydraulic Engineering Repository

Ein Service der Bundesanstalt für Wasserbau

Lai, Jihn-Sung; Tsung, S. C.; Chiew, Yee-Meng; Lee, F. Z.

Gap Scour at a Stepped Concrete Block Grade Control Structure

Verfügbar unter / Available at:

https://hdl.handle.net/20.500.11970/100282

Vorgeschlagene Zitierweise / Suggested citation:

Lai, Jihn-Sung; Tsung, S. C.; Chiew, Yee-Meng; Lee, F. Z. (2010): Gap Scour at a Stepped Concrete Block Grade Control Structure. In: Burns, Susan E.; Bhatia, Shobha K.; Avila, Catherine M. C.; Hunt, Beatrice E. (Hg.): Proceedings 5th International Conference on Scour and Erosion (ICSE-5), November 7-10, 2010, San Francisco, USA. Reston, Va.: American Society of Civil Engineers. S. 619-628. 


\title{
Gap Scour at a Stepped Concrete Block Grade Control Structure
}

\author{
J. S. Lai ${ }^{1}$, S. C. Tsung ${ }^{2}$, Y. M. Chiew ${ }^{3}$ and F. Z. Lee ${ }^{4}$
}

1. Hydrotech Research Institute, National Taiwan University No. 1, Sec. 4, Roosevelt Road, Taipei, 10617 Taiwan. Tel 886-2-33662617 jslai525@untu.edu.tw

2. Hydrotech Research Institute, National Taiwan University No. 1, Sec. 4, Roosevelt Road, Taipei, 10617 Taiwan. Tel 886-2-33662618 yinweig9@ums26.hinet.net

3. School of Civil and Environmental Engineering, Nanyang Technological University 50 Nanyang Avenue, Block N1-01a-27, 639798 Singapore. Tel +65 67905308 cymchiewantu.edu.sg

4. Department of Bioenvironmental Systems Engineering, National Taiwan University No. 1, Sec. 4, Roosevelt Road, Taipei, 10617 Taiwan. Tel 886-2-33662614 d94622004@intu.edu.tw

\begin{abstract}
Stepped concrete block grade control structures are widely used in Taiwan to protect riverbeds from degradation and to dissipate the associated high energy of flow over weirs. The grade control structures are constructed with concrete blocks with a specific gap width and drop height across the river. Large-size stones are placed in the gaps as lateral support. This type of structure is subject to the threat of edge and gap scour. In this study, the gap scour between the concrete blocks was examined by executing a series of physical model experiments in a laboratory flume. The configurations and depths of scour at the various approach discharges were monitored and measured to examine the scour characteristics between the blocks. Three phenomena were discovered: (1) the scour depths in specific areas were significantly deeper than the height of the cubic blocks, (2) the largest gap scour occurred at low discharges, and (3) eroded stones migrated along the gaps as bed load transport rather than suspension. The longitudinal gaps between the blocks were sealed to minimize stone movement. A physical model test was used to verify the method. The results indicated a maximum scour depth reduction of up to $98.7 \%$. The present paper proposes a new design methodology that includes consideration of the block heights and gap scour at low discharges.
\end{abstract}

Key Words: stepped concrete block grade control structure, gap scour

\section{INTRODUCTION}

Weirs for water intake and check dams for bridge protection are structures built across rivers. These structures raise the level of water, which increases the scour potential to the downstream riverbed. Engineers use stepped concrete block grade control structures to protect the riverbed from degradation and dissipate high flow 
energy. The structures normally are constructed using concrete blocks arranged in a stagger and descending manner (see Fig. 1a). Specific gap width and drop height between blocks are used and large-size stones are placed in the gaps as lateral support. The gaps aligned in the streamwise and transverse directions are called longitudinal and lateral gaps.
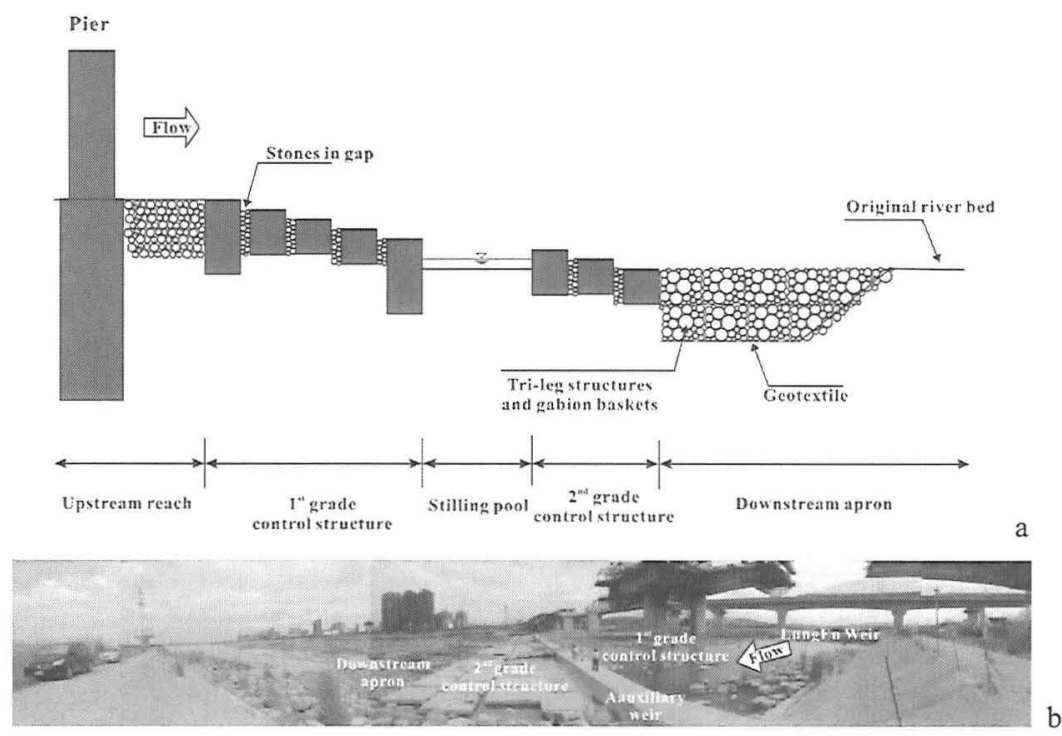

Fig 1 (a) Sketch of protection structures in a river; (b) protections downstream of Lung-En Weir, Toucian River in northern Taiwan

The stepped concrete block structures are designed based on the concept of armoring effect. The slope of the structures is steeper than that of the original riverbed slope in order to minimize construction cost. The protection structure comprises different components. Figure 1(a) illustrates the different components of a typical river bed protection work in Taiwan, namely (1) an upstream reach; (2) a first stepped concrete block grade control structure; (3) stilling pool; (4) a second stepped concrete block grade control structure; and (5) a downstream apron. Figure 1(b) shows an example of the riverbed protection downstream of the Lung-En Weir in the Toucian River in northern Taiwan. The structure consists of two sets of stepped concrete block grade control structures.

Lin $(1999,2000)$ classified the causes of failure of stepped concrete block grade control structures in Taiwan as gap scour, edge scour, head-cutting and lateral 
erosion. He found that gap scour (35.5\%) and edge scour, (22.6\%), are the dominant causes of failure. Edge scour is more visible than gap scour. Research on gap scour is few compared to the studies on edge scour. Armoring effects with reference to the relationship between sediment transport and approach flow conditions are widely studied. Raudkivi and Ettema (1982) studied the stability of an armor layer before extending it to include scour protection around piers (Raudkivi and Ettema, 1985).Worman $(1989,1992)$ studied the transport of fine sediment with an armor layer. Sumer et al. (2001) applied flow visualization techniques to examine the suction mechanism of fine sediment under an armor layer. They found that vortices that formed in the gap sucked out fine sediment particles between the gravels. They published a regression equation to estimate bed degradation due to the erosion of the fine sediment. The results of the Sumer et al. (2001) study explains the physics government sediment entrainment and mobility associated with the gap scour of stepped concrete block grade control structures. Researchers must keep in mind the significant difference in the geometrical layout and compositions of both structures in order to apply their findings. The focus of this study is gap scour. It describes the failures, which are due to gap scour in the field. This study examined the characteristics of gap scour by executing a series of physical model experiments in a laboratory flume. The configurations and scour depths at various discharges were monitored and measured to examine the physics of scouring between the blocks. The study measured and analyzed the maximum scour depths with the aim of establishing a design methodology to reduce gap scour.

\section{FIELD INVESTIGATIONS}

This study carried out a field investigation at the stepped concrete block grade control structure downstream of Highway No.1 in Ta-Chia River in central Taiwan in November 2009. The Taiwanese Highway Department built this structure in 1999 to restrain general scour or degradation of the riverbed near the bridge. Sediment was then stored upstream of the structure. The width of the structure is $840 \mathrm{~m}$. They constructed the structure using 3-m cubic concrete blocks. The height of the first-row blocks is $5 \mathrm{~m}$. The gap width between the blocks is $50 \mathrm{~cm}$. There are 20 step-drops in the flow direction and the drop height of each step is $50 \mathrm{~cm}$. The constructors connected the blocks by using steel wires. They initially submerged the second 10 steps of the stepped concrete block grade control structure with the original bed material.

Figure 2 shows pictures of the stepped concrete block grade control structure. The field investigation showed all steps exposed because of degradation downstream. The major cause of the degradation was the sediment deposition upstream, which raised the bed elevation upstream. The controller raised the water head, which resulted in high velocity movement downstream. The scour potential also increased on the downstream reach. The study found edge scour at the toe of the structure and a few blocks in the last row tilted or overturned due to extra-added support. Figure 2 reveals how the removal of stones in the gaps resulted in the weakening of the lateral supports and tilting of the blocks. The stones in the gaps provided lateral support. 
The blocks sank due to the excessive gap scour around them. Figure 2(a) shows the titling blocks and Figure 2(b) provides a closer view of the gap scour. The scour depth in some of these areas was more than $3 \mathrm{~m}$, more than the height of most of the concrete blocks. The gap widths increased because of the movement of individual concrete blocks. This further enhances stones mobility, causing the steel wires to break. The tilting and sinking of the blocks compromised the structure in terms of energy dissipation. Titling and sinking of the blocks eventually spreads in all directions. The high velocity of the water in this area flushes out most fine bed material. Figure 2(c) shows the formation of a scour hole at the upstream end of the structure. A scour hole will have a profound effect on the stability of the first row of blocks. This is a serious problem for the preservation of the overall stability of the structure.
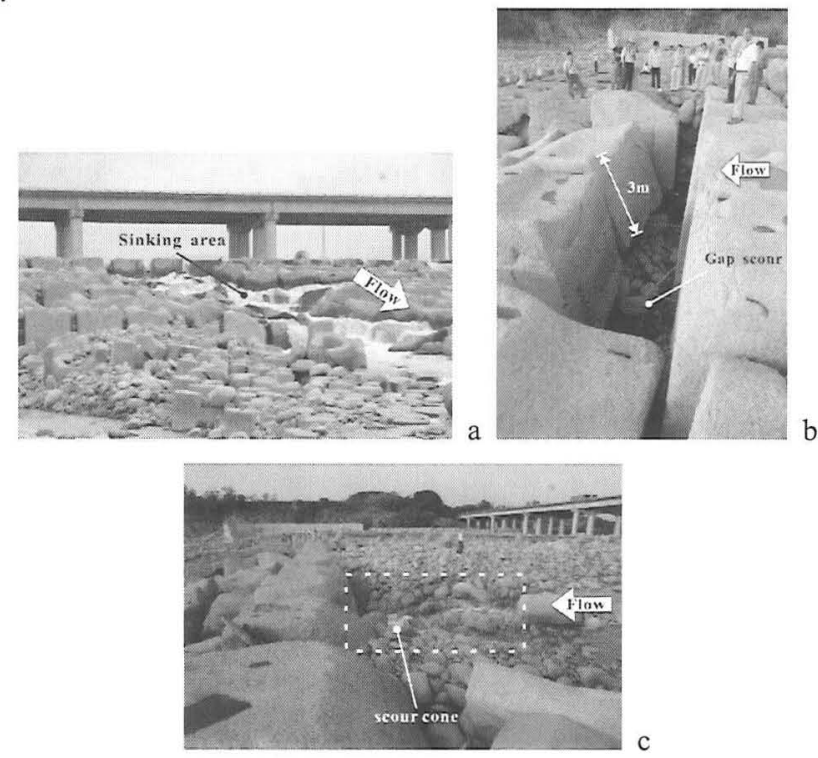

Fig 2 Failure of stepped concrete block grade control structure located downstream of Highway No.1 in Ta-Chia River in central Taiwan (November 2009): (a) blocks tilting and sinking; (b) deeper scour depth than block height; and (c) a scour hole upstream of the sinking area

\section{EXPERIMENTS}

Sumer et al. (2001) discussed how the vortices that developed in the gaps formed within the gravel have contributed to the entrainment of the fine sediment particles. Such a mode of entrainment is unlikely to take place in the present condition in which the main flow passes through the gap (Tsorng et al. 2009). Evidence from both field and laboratory observations reveal that the stones in the 
lateral gaps, gaps that are perpendicular to the main flow direction, were stable.

Conventional design of stepped concrete block grade control structures considers the stability of concrete blocks by block weight under a specific flow condition, usually at high designed discharges (Lagasse et al. 1997, Wu 2004, Guo and Chang 2006). They ignore failures due to gap scour. Recent experiences in Taiwan have exposed the fallacy of that design philosophy. A better understanding of the mechanism and the development of a design methodology that takes into consideration gap scour is necessary. This study used a physical model in order to study gap scour for design modification and a proposal for cost-effective gap scour countermeasures.

It was necessary to determine the general block geometry and stone dimension to match the real flow and scour characteristics. Most of the stepped concrete block grade control structures in Taiwan consist of five steps with an individual step drop-height of $50 \mathrm{~cm}$. The projection area of the block is $2 \times 2 \mathrm{~m} 2$ and the gap width is $50 \mathrm{~cm}$. The average median stone size used to fill the gap is about $20 \mathrm{~cm}$. We fixed the upstream and downstream beds of the structure since this study only considered the scour between the blocks. A rectangular flume was used that is $30 \mathrm{~cm}$ in width, $60 \mathrm{~cm}$ in height, and $1500 \mathrm{~cm}$ in length located at the Hydrotech Research Institute, National Taiwan University to carry out the experiments. At least six blocks in each row was determined in order to display the global scour patterns and avoid boundary effect. A 1/50 scaled model was built in the flume using scaled blocks with an area = $4 \times 4 \mathrm{~cm} 2$. The block heights were at least $25 \mathrm{~cm}$ to measure the equilibrium scour depth in the gaps. The scaled gap width and drop height of each step was $1 \mathrm{~cm}$. A uniform sand with median grain size $=3.56 \mathrm{~mm}$ was used to fill the gaps. Figure 3 shows the model design of the experiments. The researchers simulated the slope of 0.01 in the model tests since the longitudinal bed slope of rivers in Taiwan generally ranges from 0.01 to 0.001 . The study adopted a clear-water condition without sediment influx from upstream. The bed elevation in the gaps was the same as the ambient block surfaces before the tests. We performed two sets of experiments, the "all-gaps-opened" and "only-lateral-gaps-opened" conditions.

The scour depth variations were monitored in both cases to ensure the equilibrium scour condition. The scour hole approached its equilibrium stage in approximately 15 minutes. The measurement of the bed elevation in both the longitudinal and lateral gaps continued for 40 minutes. The average bed elevation in the stream wise direction was the mean value of all the measured data in the transverse direction at the same streamwise positions. This study tested the scour depth variation for five different unit discharges, which varied from 0.008 to 0.051 $\mathrm{m} 2 / \mathrm{s}$. Table 1 summarizes the test conditions of all the experiments conducted in this study. 


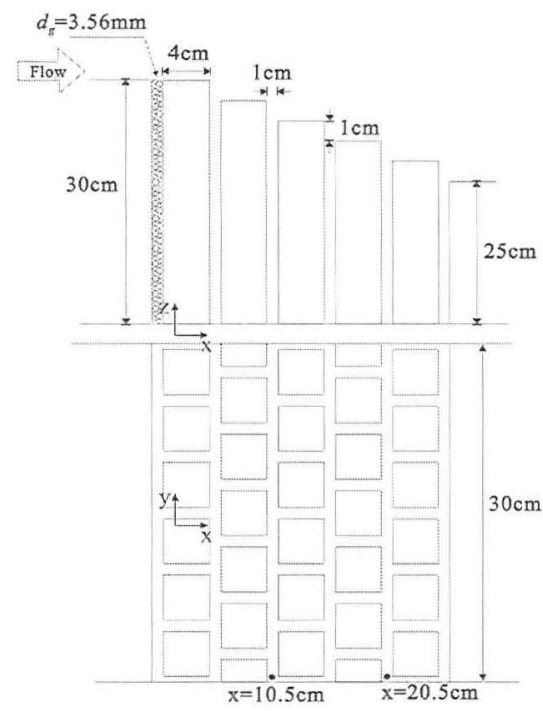

Fig 3 Sketch of scaled physical model and dimensions (side and top view)

Table 1 Experimental conditions and measured data: $q$ - unit discharge; $d_{50}-$ diameter of stone in the gaps; $S_{b}$ - flume slope,$S_{r m}$ - slope of structure;

$y_{b m}$-lowest bed elevation; $x_{s}$ - the corresponding position of $y_{b m} ; y_{b o}$-original bed elevation at $x_{s}$; $e$-maximum scour depth

\begin{tabular}{|c|c|c|c|c|c|c|c|c|}
\hline Run & {$\left[\begin{array}{c}\mathrm{q} \\
{\left[\mathrm{m}^{2} / \mathrm{s}\right]}\end{array}\right.$} & $\begin{array}{c}\mathrm{d}_{50} \\
{[\mathrm{~mm}]}\end{array}$ & $S_{b}$ & $\mathrm{~S}_{\mathrm{rm}}$ & $\begin{array}{c}\mathrm{y}_{\mathrm{bm}} \\
{[\mathrm{cm}]}\end{array}$ & $\begin{array}{c}\mathbf{x}_{\mathrm{s}} \\
{[\mathrm{cm}]}\end{array}$ & $\begin{array}{c}\mathbf{y}_{\mathrm{bo}} \\
{[\mathrm{cm}]}\end{array}$ & $\begin{array}{c}\mathrm{e} \\
{[\mathrm{cm}]}\end{array}$ \\
\hline GS1 & 0.0089 & \multirow{5}{*}{3.56} & \multirow{5}{*}{0.01} & \multirow{5}{*}{0.20} & 21.98 & 15.50 & 27.00 & 5.02 \\
\hline GS2 & 0.0188 & & & & 21.65 & 12.00 & 28.00 & 6.35 \\
\hline GS3 & 0.0314 & & & & 22.31 & 15.50 & 27.00 & 4.69 \\
\hline GS4 & 0.0433 & & & & 22.91 & 15.50 & 27.00 & 4.09 \\
\hline GS5 & 0.0505 & & & & 23.45 & 15.50 & 27.00 & 3.55 \\
\hline GSP1 & 0.0089 & \multirow{5}{*}{3.56} & \multirow{5}{*}{0.01} & \multirow{5}{*}{0.20} & 28.75 & 5.50 & 29.00 & 0.25 \\
\hline GSP2 & 0.0188 & & & & 29.92 & 0.50 & 30.00 & 0.08 \\
\hline GSP3 & 0.0314 & & & & 25.79 & 20.50 & 26.00 & 0.21 \\
\hline GSP4 & 0.0433 & & & & 25.84 & 20.50 & 26.00 & 0.16 \\
\hline GSP5 & 0.0505 & & & & 28.80 & 5.50 & 29.00 & 0.20 \\
\hline
\end{tabular}




\section{RESULTS AND DISCUSSIONS}

\section{Mechanics of Gap Scour}

Figure 4 shows the temporal development of the measured scour depth for Test GS3 at $\mathrm{x}=10.5$ and $20.5 \mathrm{~cm}$, where $\mathrm{x}$ is the horizontal distance measured from the upstream end of the structure (see Fig. 3). The figure shows that the rate of scour is high in the initial stages of the test. Figure 5 presents the process of gap scour evolution. The stones near the surface of the block eroded as soon as the flow arrived, Figure 5(a). Gap scouring occurred in the first three rows. Figure 5(b) shows the gap scour at $\mathrm{t}=6$ seconds. It indicates how the eroded stones migrated along the longitudinal gaps downstream with no apparent sediment suspension. Some stones spun behind the block due to flow separation within the wake created by the downstream flow. The measured temporal scour depth development curves show that the scour rates gradually decreased with time. Figure 5(c) shows the gap scour at $\mathrm{t}=$ 30 seconds. The stones driven by the flow in the gaps continued to move slower downstream. The downstream flow temporarily deposited some of the stones behind the final-row of blocks. These stones eventually washed away. The stones in the gaps stabilized as the equilibrium state approached. The behavior of stone mobility in the gaps was similar to bed load transport dominated by gap flows.

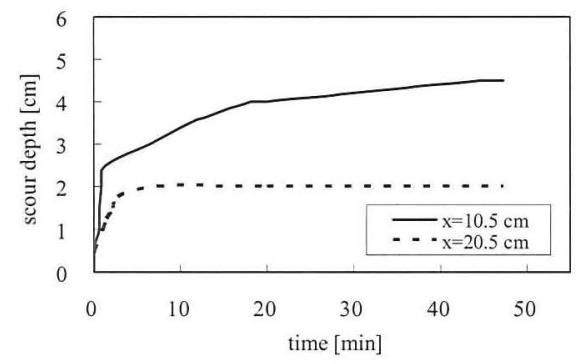

Fig 4 Temporal development of gap scour at $\mathrm{x}=10.5$ and $20.5 \mathrm{~cm}$ (monitoring position referred to Figure 3)
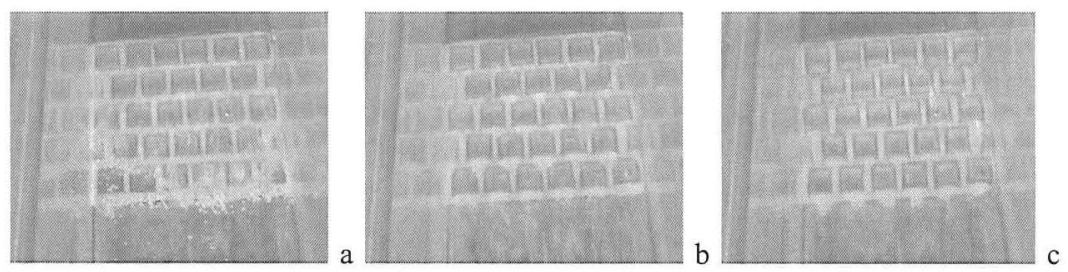

Fig 5 Gap scour evolution of Test GS3 at (a) 2 sec; (b) $6 \mathrm{sec}$; (c) $30 \mathrm{sec}$ 


\section{Scour of "All-Gaps-Opened" Conditions}

Figure 6 shows the average measured bed profiles for Tests GS1 - GS5. Table 1 contains the measured data, which includes the lowest bed elevation, their corresponding position, and the maximum scour depth. The figure shows that the average bed profiles for all five tests were similar. The bed elevation decreased from the first-row of blocks reaching the minimum level near the third-row of blocks. The minimum level was approximately $15 \mathrm{~cm}$ downstream from the leading edge of the structure and coinciding with the lateral gap behind the third-row of blocks. The bed elevation increased beyond this location.

The measured data show that the maximum scour depth for all the tests was e $=6.35 \mathrm{~cm}$, which is for Test GS2, with unit flow rate, $\mathrm{q}=0.0188 \mathrm{~m} 2 / \mathrm{s}$. The scour depth in the gap of a stepped concrete block grade control structure was not directly proportional to the approach discharge. The scour depth increased as the discharge increased initially. It then decreased with a further increment of the approach flow rate. Serious gap scour occurs at a low or moderate rate of flow. The design of a stepped concrete block grade control structure should be re-examined in light of this finding. Furthermore, the gap scour depth at the first to third-row of blocks could potentially exceed $4 \mathrm{~cm}$, which was deeper than the height of the adjacent cubic blocks. The gaps can potentially be completely entrained leaving no lateral support for the concrete blocks. The height of the concrete blocks used in Taiwan is insufficient. Field investigation supported this conclusion, Figure 2a.

The experimental results show that the design of stepped concrete block grade control structures should consider the stability of a single concrete block under a designed flow condition and the extent of the gap scour depth. The designed height of a block must be more than the estimated scour depth and the block height should be dependent on its location.

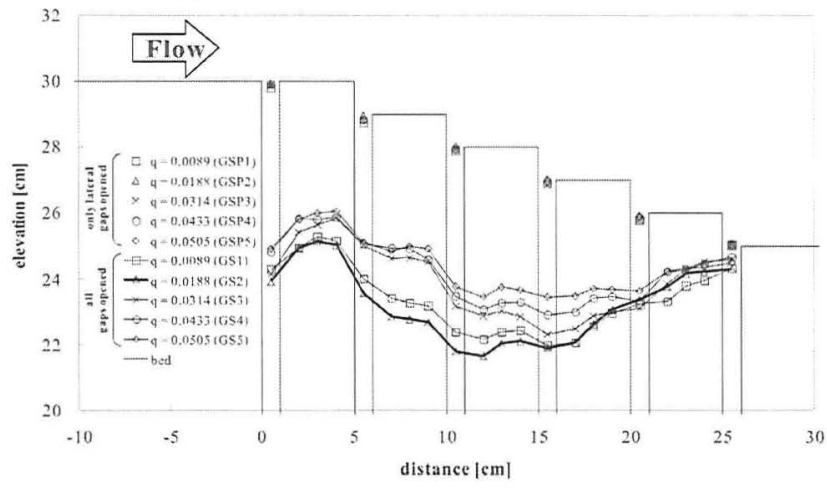

Fig 6 Mean bed form profiles in the gaps 


\section{Scour of "Only-Lateral-Gaps-Opened" Conditions}

The results for the condition of "all-gaps-opened," Tests GS1 -GS5, show how the stones migrate along the lateral and longitudinal gaps in the downstream direction. We proposed to open only the lateral gaps and validate the performance (Tests GSP1-5). Figure 6 and Table 1 show the average bed elevation and measured data for the "only-lateral-gaps-opened" condition. The maximum scour depth for all the tests was $0.25 \mathrm{~cm}$ (Test GSP1), which was significantly lower than the $6.35 \mathrm{~cm}$ for the "all-gaps-opened" condition. Entrainment of the stones from the gaps resulted from the vortices in the gaps when only lateral gaps existed in a stepped concrete block grade control structure. The main flow above the lateral gaps drived the vortices in the gaps. The required mean velocity of flow to suspend the $3.56-\mathrm{mm}$ stones on a flat flume was $115 \mathrm{~m} / \mathrm{s}$ (Hjulstorm, 1935, Yang 1996). The maximum velocity of flow over the current stepped concrete block grade control structure for all cases was $112 \mathrm{~m} / \mathrm{s}$ (at $\mathrm{x}=26 \mathrm{~cm}$, Test GSP5). The velocities in the gaps were less than the requirement for the initiation of sediment suspension.

The experimental results show that the presence of longitudinal gaps promoted the development of gap scour. The scour depth appeared to be unrelated to the approach discharge in contrast to the all-gaps-opened Tests GS1-5. The reduction of the bed elevation from $6.35 \mathrm{~cm}$ (Test GS2) to $0.08 \mathrm{~cm}$ (Test GSP2) was significant. The test showed that sealing the longitudinal gaps could effectively reduce the scour depth by up to $98.7 \%$. Solid or impermeable material could be considered to seal the longitudinal gap.

\section{CONCLUSIONS}

This study identifies the main causes for failure of stepped concrete block grade control structures in Taiwan through field investigations. One of the main causes of failure in these structures is gap scour. The scaled physical model experiments with different approach discharges were conducted to study this problem. The longitudinal gaps of the structure were sealed to reduce the extent of gap scour. This method showed a significant decrease in development of scour holes.

The study considered the five-stepped concrete block grade control structure used in Taiwan. The shape of the average bed profiles in the longitudinal gaps was similar for different approach discharges. The experimental results indicated the maximum scour depth was in the middle of the stepped concrete block grade control structure. The experimental results also showed that the scour depth in the first three rows of blocks was deeper than the height of the cubic blocks. The designed block height used in Taiwan was insufficient. The scour depth in the gaps was not proportional to the approach discharge. The maximum scour depth in this study occurred at a relatively low approach discharge. The designers of these structures need to consider gap scour at comparatively low or intermediate discharge and adequate block heights. The experimental results showed that sealing the longitudinal gaps offers a promising solution to keep the stones within the lateral gaps. 


\section{ACKNOWLEDGEMENTS}

Financial support for this work was provided by the Water Resources Planning Institute, Taiwan. We thank Ms.Y. L. Chen for her help in data measurement and analyses.

\section{REFERENCES}

Lin, C (1999). "Study on technology and tactics for scour prevention of cross-river structures." Public Construction Commission. (in Chinese)

Lin, C (2000). "Guidelines for preventions of scour due to free overfall and hydraulic jump." Sinotech Engineering Consultant. (in Chinese)

Raudkivi, A.J. and Ettema, R. (1982). "Stability of armour layers in rivers." $J$. Hydraul Div., 108 (9): 1047-1057.

Raudkivi, A.J. and Ettema, R. (1985). "Scour at cylindrical bridge piers in armored beds." J. Hydr. Engrg., 111 (4): 713-731.

Worman, A. (1989). "Riprap protection without filter layers." J. Hydr. Engrg., 115 (12): 1615-1630.

Worman, A. (1992). "Incipient motion during static armoring." J. Hydr. Engrg., 118 (3): 496-501.

Raudkivi, A. J. (1998). "Loose boundary hydraulics." Balkema.

Sumer, B.M., Cokgor, S. and Fredsoe, J. (2001). "Suction removal of sediment from between armor blocks." J. Hydr. Engrg., 127 (4): 293-306.

Tsorng, S.J., Yang, Z.S., and Lai, J.S. (2009). "Measurements of flow field between blocks in various geometries." $18^{\text {th }}$ Conference of Hydraulic Engineering, PingTung, Taiwan, H-11. (in Chinese)

Lagasse P.F., Byars M.S., Zevenbergen L.W. and Clopper, P. E. (1997). "Bridge Scour and Stream Instability Countermeasures." Federal Highway Administration, FHWA-HI-97-030.

Wu, C.S. (2004). "Design of stepped concrete block grade control structure." Master Thesis, Hydraulics \& Ocean Engineering, NCKU, Tainan, Taiwan. (in Chinese)

Guo, Y.H. and Chang, Y.Z. (2006). "Failure mechanisms of flexible grade control and protections. "Hydraulics, (16): 201-210. (in Chinese)

Hjulstorm, F. (1935). "The Morphological Activity of Rivers as Illustrated by River Fyris." Bulletin of Geological Institute, Uppsala, vol.25, chap3.

Yang, C.T. (1996). "Sediment Transport - theory and practice." McGraw-Hill. 